\title{
Method of calculating the gear ratios of the cones of tricone drill bits
}

\author{
Javokhir Toshov ${ }^{1 *}$, Bakhtiyor Baratov ${ }^{1}$, and Umid Baynazov ${ }^{2}$ \\ ${ }^{1}$ Tashkent State Technical University, Department of Mining Electromechanics, 2 University St., \\ 100095 Tashkent, Republic Uzbekistan \\ ${ }^{2}$ Department of Automobile and Technological Transport, JSC "Uzbekugol", 100011 Tashkent, \\ Republic Uzbekistan
}

\begin{abstract}
The process of rock destruction under dynamic impact on it through two technological criteria in the form of specific contact and specific volumetric fracture works is evaluated. Specific contact and specific volumetric fracture work are used to study the physical and mechanical properties of rocks. The efficiency of rock destruction during well drilling with tricone bits functionally depends on the relative specific contact and specific volumetric fracture work. It is stated that the criteria for evaluating the performance of tricone bits in certain forms are functions of the triad: bit-rock-energy. The disclosed physical nature of the kinetic criteria and the obvious functional dependence on the geometric parameters of these drill bits are an objective basis for constructing a methodology for improving the dynamics of new designs and modifications. The parameters of the kinetic passport of the bit are calculated and presented in tabular and graphical forms as functions corresponding to their coordinates of the cones of the roller cutters and the bottom of the well. Experience in solving optimization problems based on a comparative analysis of kinetic (dynamic) criteria has shown that a) when improving almost any design of a cone bit, it is necessary to use the initial geometrical parameters of the buttons and their number b) to ensure that the supports of adjacent cones are equally loaded along the path of leveling the minimum volumetric fracture work of crowns adjacent cones.
\end{abstract}

\section{Introduction}

Today, the modern process of drilling wells around the world has two aspects: technical the development, design and manufacture of drilling rock cutting tools and technological the optimal choice of drilling tools in accordance with the physical and mechanical conditions of the bottom hole and determining the optimal drilling conditions: axial loads, rotational velocity of tools and the amount of fluid (air) supplied to the bottom of the well [1]. These issues currently remain unresolved, because bottom hole conditions differ by geological region. Therefore, not in all cases, the optimization of the choice of the drill bit will be effective, which equally applies to the process of optimizing drilling modes.

\footnotetext{
*Corresponding author: jtoshov@,tdtu.uz
} 
The number of drilling rock cutting tools used has a general tendency to increase both in time and quantity, and in type [2,3]. This is due to the fact that the volume of drilling operations is increasing, the conditions for the destruction of rocks are becoming more complicated, and the rock pressure is increasing at considerable depths. In this regard, optimization of drilling modes and the selection of a rational type of drill bit are prevalent.

The performance of the bit in many ways determines the success of drilling operations. Drill bits come in different sizes, types and shapes and are designed to drill various rocks of strength. Creating an optimal drill design requires a balance between the speed, stability and durability of drilling, which today is one of the difficult tasks assigned to engineers [4 - 7]. The development of new types of highly efficient rock-cutting drilling tools is an urgent problem of the science and practice of mining, the solution of which helps to increase the economic efficiency of enterprises.

In order for theoretical studies in the field of rock cutting tools to be relevant and significant in the further development of mathematical modeling, it is necessary to determine the correctness and effectiveness of the criteria for evaluating the work of a drill bit of a particular structure or its modification, it is necessary to state the physical essence of these criteria or express them as functions of geometric parameters of bits and physical and mechanical properties of drilled rocks.

\section{Mathematical modeling of specific contact and volumetric fracture works}

It has been established that the process of rock destruction under dynamic impact on it is most rationally assessed through two technological criteria in the form of specific contact and specific volumetric fracture works. Mathematically, they are represented as follows:

$$
A_{S}=\frac{A_{t}}{S}
$$

where $A_{\mathrm{s}}$ is specific contact fracture work, $\mathrm{N} / \mathrm{mm}^{2} ; A_{t}$ is total work spent on deformation and destruction of the rock by indentation stamp, N; $S$ is flat base area of a cylindrical stamp, $\mathrm{mm}^{2}$.

$$
A_{v}=\frac{A_{t}}{V}
$$

where $A_{v}$ is specific volumetric fracture works, $\mathrm{N} / \mathrm{mm}^{3} ; A_{t}$ is total work spent on deformation and destruction of the rock by indentation stamp, $\mathrm{N} ; V$ is deformed rock volume, $\mathrm{mm}^{3}$.

The specific contact and specific volumetric fracture work, respectively, in forms (1) and (2) are objective energy criteria for static rock destruction under a stamp [8].

Therefore, they are suitable only for studying the physical and mechanical properties of rocks.

The criteria in the form of (1) and (2), being the energy criteria of the physical and mechanical properties of rocks during their static destruction, were objective prototypes of the criteria for assessing the performance of drill bits in the forms of relative specific contact and volumetric fracture works, the analytical structure of which is presented below in the forms (3) and (4):

$$
A_{j}^{\prime}=\frac{S_{j} F_{j} i}{\Delta S_{j}},
$$

where $A_{j}^{\prime}$ is relative specific contact work of buttons' destruction of $j$-th crown, N/mm $; S_{j}$ 
is contact path of a button of a unit area of the $j$-th conventional crown at one-act entry into contact with the bottom surface of the well, mm; $F_{j}$ is force of resistance to movement of button of a unit area of $j$-th conventional crown in contact with the rock at the bottom of the well, $\mathrm{N} ; i$ is gear ratio of cone; $\Delta S_{\mathrm{j}}$ is the contact area of the top of the button of $j$-th crown cones of single length and width, $\mathrm{mm}^{3}$.

$$
A_{k}^{\prime \prime}=\frac{S_{j, k} F_{j} z_{j} d_{j} i}{V_{k}},
$$

where $A_{k}$ " is relative specific volumetric work of button destruction of the $j$-th crown at the $k$-th annular bottomhole, $\mathrm{N} / \mathrm{mm}^{2} ; S_{j, k}$ is the contact path of the button of the $j$-th crowns at the $k$-th annular faces of the well, mm; $z_{j}$ is the number of buttons on the $j$-th crown, pcs; $d_{j}$ is the number of conventional crowns of unit width on the $j$-th real crown, pcs.; $V_{k}=2 \pi R_{k} D_{k} \delta_{k}$ is rock volume of the $k$-th annular bottom hole of a well with a thickness $\delta$ per fracture, $\mathrm{mm}^{3} ; R_{k}$ is average radius of the $k$-th annular bottomhole, mm; $D_{k}$ is the width of the $k$-th annular bottomhole, mm; $\delta_{k}$ is predetermined thickness (depth) of the $k$-th annular bottom hole, mm. Note: When calculating the criteria in forms (3) and (4) it is considered to have $F_{j}=1, \Delta S=1$.

The criteria for evaluating the performance of tricone bits in the form of (3) and (4) are usually called kinetic, and the tabular and graphical forms of their presentation by the kinetic passport of the bit.

Using these formulas in the process of analyzing the dynamics of the armament (buttons) of these bits without computer technology is ineffective.

It should be noted that the kinetic passports are calculated and presented in tabular and graphical forms as functions corresponding to their coordinates of the cone crowns and the bottom of the well. Therefore, the criteria in forms (3) and (4) for tricone bits are mathematically logical to write in the following forms.

$$
\begin{gathered}
\left(A_{j}^{\prime}\right)_{I}=\frac{S_{j} F_{j} i}{\Delta S_{j}},\left(A_{j}^{\prime}\right)_{I I}=\frac{S_{j} F_{j} i}{\Delta S_{j}},\left(A_{j}^{\prime}\right)_{I I I}=\frac{S_{j} F_{j} i}{\Delta S_{j}}, \\
\left(A_{k}^{\prime \prime}\right)_{I}=\left(\frac{S_{j, k} F_{j} z_{j} d_{j} i}{V_{k}}\right)_{I}+\left(\frac{S_{j, k} F_{j} z_{j} d_{j} i}{V_{k}}\right)_{I I}+\left(\frac{S_{j, k} F_{j} z_{j} d_{j} i}{V_{k}}\right)_{I I I} .
\end{gathered}
$$

Here, the indices $I, I I$ relate, respectively, to the first and second cones. If the crowns of adjacent cones work on one of the annular faces of the well, then volumetric work is summed up, while contact work is not subject to summation. This is because the criteria $A_{j}^{\prime}$ is the criteria for the wear rate of the corresponding crowns of the cones, and the criteria $A_{k}{ }^{\prime \prime}$ is the criteria for the intensity of the destruction of the rock of the corresponding annular faces of the wells, on which, in general, the buttons of both cones work.

Such is the physical nature of the criteria $A_{j}^{\prime}$ and $A_{k}{ }^{\prime \prime}$. It can be interpreted as follows:

$$
\begin{gathered}
A_{\max }^{\prime} \sim \frac{1}{T_{2}}, \\
A_{\min }^{\prime \prime} \sim V_{\mathrm{M}},
\end{gathered}
$$

where $T_{2}$ is mechanical drilling time, hour; $V_{s p}$ is mechanical drilling speed, $\mathrm{m} / \mathrm{h}$.

Given that

$$
H=V_{s p} T_{2},
$$

(where $H$ is Penetration of a bit, $\mathrm{m}$ ) then it can be written 


$$
H \sim A_{\min }^{\prime \prime} \frac{1}{A_{\text {max }}^{\prime}} .
$$

From here, the connection between the criteria and the classical formula for the cost of a meter of penetration is easily seen [9]:

$$
C=\frac{C_{1}\left(T_{1}+T_{2}+T_{3}\right) C_{2}}{H},
$$

where $C$ is the cost of a meter of penetration when drilling wells, $\$ ; C_{1}$ is the cost of one hour of drilling rig operation, $\$ ; T_{1}$ is time of preparatory operations, hour; $T_{2}$ is drilling time, hour; $T_{3}$ is time of hoisting operations, hour; $C_{2}$ is the cost of the drill bit, $\$ ; H$ is Penetration of a bit, $\mathrm{m}$.

Now the economic criterion (9) is presented in the form:

$$
C \sim \frac{\mathrm{C}_{1}\left(T_{1}+\frac{1}{A_{\max }^{\prime}}+T_{3}\right)+C_{3}}{\frac{1}{A_{\max }^{\prime}} \cdot A_{\min }^{\prime \prime}} .
$$

The record of the economic criterion for evaluating the performance of drill bits in the form of (10) confirms the objectivity of the technological criteria in the form of (3) and (4).

From here, one can easily see the way of minimizing the economic criterion (9) through technological criteria in the form of (3) and (4) in the following:

- criterion value $A^{\prime}{ }_{\text {max }}$ should be as low as possible;

- criterion value $A^{\prime \prime}{ }_{\text {min }}$ should be as high as possible.

It is obvious. We will dwell on the methodology for improving tricone bits in the general case below.

Now we need to show that the criteria $A_{j}^{\prime}$ and $A_{k}{ }^{\prime \prime}$ are functions of the geometrical parameters of drill bits, varying which can, within certain limits, change the values of these criteria and, therefore, solve optimization problems to improve the dynamics of armament of tricone bits.

How the criteria $A_{j}^{\prime}$ and $A_{k}{ }^{\prime \prime}$ depend on the geometrical parameters of the bit is easiest to follow in the process of constructing their analytical structures. All this is based on the method of calculating the main parameter of these criteria - the contact paths of the cone buttons at a given depth of immersion in the rock.

The criterion for assessing the performance of tricone drill bits is considered in the following questions:

- analytical structure of the criteria;

- physical meaning of the criteria;

- possibility of criteria for evaluating the performance of tricone bits when solving optimization problems.

It is proposed to take the following functional dependencies as criteria for assessing the performance of tricone drill bits.

Relative specific contact work [10]:

$$
A_{j}^{\prime}=\frac{S_{j} F_{j} i}{\Delta S_{j}} .
$$

In tri-cone bits each cone works independently of two adjacent ones. Therefore, the relative specific contact fracture work is calculated separately for each cone, and the 
representation of these values as a whole for the bit should be:

$$
\left(A_{j}^{\prime}\right)_{I}=\frac{S_{j} F_{j} i}{\Delta S_{j}},\left(A_{j}^{\prime}\right)_{I I}=\frac{S_{j} F_{j} i}{\Delta S_{j}},\left(A_{j}^{\prime}\right)_{I I I}=\frac{S_{j} F_{j} i}{\Delta S_{j}} .
$$

Relative specific volumetric fracture work:

$$
A_{k}^{\prime \prime}=\frac{S_{j, k} F_{j} z_{j} d_{j} i}{V_{k}} .
$$

Since the specific volumetric fracture work is associated with the volume of rock at the annular bottom of the well, the record of this expression in the general case will be as follows:

$$
\left(A_{k}^{\prime \prime}\right)=\left(\frac{S_{j, k} F_{j} z_{j} d_{j} i}{V_{k}}\right)+\left(\frac{S_{j, k} F_{j} z_{j} d_{j} i}{V_{k}}\right)+\left(\frac{S_{j, k} F_{j} z_{j} d_{j} i}{V_{k}}\right),
$$

where $A_{j}$ is the relative specific contact work of the destruction of the button of the $j$-th crown, N/mm; $S_{j}$ is contact path of the button of the $j$-th crown for single act of their interaction with the bottom surface of the well, $\mathrm{mm} ; F_{j}$ is force of resistance to movement of button of the $j$-th crown in contact with the surface of the bottom of the well, $\mathrm{N} ; i$ is gear ratio of a cone.

Below are the algorithms and programs for calculating kinetic characteristics using a PC.

As can be seen, the criteria in forms (11) and (12) are explicit functions of the entire set of geometrical parameters of these drill bits.

The implicit dependence of these criteria lies in the set value of the introduction (immersion) of the cone teeth in the breed $\delta$. Naturally, to assume that this value is in general an unknown function for us from the same geometric parameters of the drill bits, from the energy parameters communicated to the teeth, from the physical and mechanical properties of the rocks under certain conditions (constrained, lightened) at the bottom of the well, i.e.

$$
\delta=\delta(B, R, E)
$$

To date, this function has not been explicitly built, and is unlikely to be built in the future.

But this fact is not an obstacle when studying the performance of tri-cone bits, all other things being equal, i.e. for a given value of $\delta$. Moreover, we also know the limits of variation of this quantity:

$$
0 \leq \delta \leq h_{3}
$$

where $h_{3}$ is the height of the button out of the cone, $\mathrm{mm}$.

Thus, it can be argued that the criteria for evaluating the performance of tri-cone bits in the form of (11) and (12) are functions of the triad: bit-rock-energy.

The disclosed physical nature of the kinetic criteria and the obvious functional dependence on the geometric parameters of these drill bits are an objective basis for constructing a methodology for improving the dynamics of new designs and modifications.

Experience in solving optimization problems based on a comparative analysis of kinetic (dynamic) criteria has shown the following.

1. When improving almost any design of a cone bit, it is necessary to use the initial geometric parameters of the buttons and their number $Z$.

2. The most promising optimization task is the task of ensuring the equal loading of the bearings of adjacent cones on the path of leveling the minimum volumetric work of destruction of the crowns of adjacent cones. 


\section{Performance optimization of tricone bits}

In the process of long-term theoretical and experimental studies of the operability of tricone drill bits, the following provisions have been established.

1. The effectiveness of the destruction of the rock when drilling wells with tri-cone bits functionally depends on two kinetic criteria:

- relative specific contact work of destruction (11):

$$
\left(A_{j}^{\prime}\right)_{I}=\frac{S_{j} F_{j} i}{\Delta S_{j}},\left(A_{j}^{\prime}\right)_{I I}=\frac{S_{j} F_{j} i}{\Delta S_{j}},\left(A_{j}^{\prime}\right)_{I I I}=\frac{S_{j} F_{j} i}{\Delta S_{j}},
$$

- relative specific volumetric work of destruction (14):

$$
\left(A_{k}^{\prime \prime}\right)_{I}=\left(\frac{S_{j, k} F_{j} z_{j} d_{j} i}{V_{k}}\right)_{I}+\left(\frac{S_{j, k} F_{j} z_{j} d_{j} i}{V_{k}}\right)_{I I}+\left(\frac{S_{j, k} F_{j} z_{j} d_{j} i}{V_{k}}\right)_{I I I} .
$$

2. Kinetic criteria for evaluating the performance of tri-cone drill bits in the form of (11) and (12).

3. Kinetic criteria are explicit functions of the geometric parameters of the tri-cone drill bits (see (11) and (12)).

4. In the physical sense, the relative specific contact work of fracture in the form (11) determines the intensity of the abrasive wear of the button of the $j$-th cones of the cones (see (5)):

$$
A_{j}^{\prime} \sim \frac{1}{\mathrm{~T}_{2}}
$$

5. According to the physical meaning, the relative specific volumetric fracture work in the form (12) determines the intensity of rock fracture by the button of the $j$-th cones of cones at the $k$-th annular faces of the well (see (6)):

$$
A_{k}^{\prime \prime} \sim \mathrm{V}_{\mathrm{M}} \text {. }
$$

The first and second provisions reveal the objectivity of kinetic criteria, the third indicates the real possibility of changing kinetic criteria by varying the geometrical parameters of the drill bits, the fourth and fifth determine the purposefulness of the change in kinetic criteria in the process of improving drilling tri-cone bits.

It should be kept in mind that the values of the specific contact and volumetric fracture works are different for the buttons working on the annular faces of the well, which are overlapped by the crowns of adjacent cones. Therefore, it is necessary to focus on extreme values of specific contact and specific volumetric fracture works.

Experience in solving optimization problems based on a comparative analysis of kinetic (dynamic) criteria has shown the following.

1. When improving almost any design of a cone bit, it is necessary to use the initial geometric parameters of the teeth and their number $Z$.

2. The most promising optimization problem is the task of ensuring the equal loading of the supports of adjacent cones on the path of leveling the minimum volumetric work of destruction of the crowns of adjacent cones.

Below we give a specific example of improving the geometry of armament and choice, based on its existing geometry, a more efficient design of the same type of bit for a given geological and technical conditions. 


\section{Recommendations for improving the design and operation of drill bit III 215.9 SM}

Notation keys: $j$ is crown number starting from the periphery; $k$ is serial number of the annular bottom hole corresponding to the $j$-th crown; $R$ is average radius of the corresponding annular face, $\mathrm{mm} ; D$ is length of the conditional crown (not more than 4 $\mathrm{mm}$ ), the cone which overlaps the corresponding annular bottom hole, $\mathrm{mm} ; Z_{\mathrm{I}}, Z_{\mathrm{II}}, Z_{\mathrm{III}}$ are number of buttons on the crowns, respectively, on the first, second and third cones, pcs.; $i$ is gear ratio of the cone; $A^{\prime}$ is relative specific contact work of destruction along the cones of the cone, $\mathrm{N} / \mathrm{mm}^{2} ; A^{\prime \prime}$ is relative specific volumetric fracture work along the annular sections of the bottom of the well, $\mathrm{N} / \mathrm{mm}^{3}$.

The purpose of these recommendations is to increase the efficiency of the cone bit due to its more perfect geometry and rational operation in the given geological and technical conditions.

These recommendations have two aspects: technical - the recommendation of a more perfect bit geometry (design), technological - the recommendation of a more rational type bit design for given geological and technical drilling conditions.

Tri-cone drill bits fail, having exhausted their potential capabilities either in arming of the cones or in their supports. Moreover, these phenomena - wear (chipping) of the cone button and wear of the supports, as a rule, are local in nature, i.e. depreciation of the buttons of the cones and their supports occurs ahead of, respectively, on one of the crowns at one of the cones $[10,11]$.

All this is in full accordance with the kinetic characteristics: $A^{\prime}$ is the specific relative contact work of the destruction, $A^{\prime \prime}$ is the specific relative volumetric work of the destruction, or rather with the ratios of their extreme values.

The specific contact work of the fracture $A^{\prime}$ characterizes the relative intensity of abrasive wear of the teeth of the crowns of adjacent cones, and the specific volumetric work of the fracture $A^{\prime \prime}$ characterizes the relative intensity of the destruction of rock in adjacent annular borehole faces.

According to the values $A^{\prime}{ }_{\text {max }}$, it is possible to accurately predict which of the crowns of adjacent cones the bits will wear out ahead of time, and according to the values of $A^{\prime \prime}$ min which button from crowns of the cones have a high probability of chipping and which of the crowns determines the upper limit of the real mechanical drilling speed, which supports of adjacent cones will be more loaded and therefore has advanced wear.

These values are calculated and given in the kinetic passports below. Extreme values in passports are emphasized in order to facilitate the perception of a comparative analysis of the work of bits according to their kinetic characteristics in the process of developing relevant recommendations.

The first part gives recommendations on the technical aspect. The development of such recommendations is possible in three consistent directions:

1. On the path of equal loading of the supports of adjacent cones, i.e. on alignment $A^{\prime \prime}{ }_{\min } \mathrm{I}$, $A^{\prime \prime}{ }_{\min }$ II, $A^{\prime \prime}{ }_{\text {min III. }}$.

2. On the way to increase the total (minimum) intensity of rock destruction, i.e. on increase $A^{\prime \prime}$ min.

3. On the way we save carbide armament, i.e. to remove excess buttons on the crowns, where $A^{\prime \prime}$ is far superior than $A^{\prime \prime}$ min.

The economic effect will be determined:

- in the first case - by increasing the bit resistance;

- in the second case - by increasing the mechanical drilling speed;

- in the third case - by reducing the cost of the drill bit. In the general case, an effective solution can also be found when crossing these paths. 
The development of recommendations is based on the solution of the following sequence of matters;

1 Analysis of the kinetic passport of the basic design of the drill bit.

2. Determining ways to improve its design.

3. The definition of a new combination of geometrical parameters of the bit, giving the best kinetic passport.

4. A comparative analysis of the health of the recommended design of the bit with the base according to their kinetic passports.

The second part provides developed recommendations for the rational operation of this design of the drill bit, i.e. their technological aspect. Moreover, the recommendations are given for both the basic and advanced design according to the recommendations of the technical aspect. These recommendations are developed taking into account both the possible replacement of a particular type of bit with this design, as well as the possible replacement of this bit with a known best design.

The development of this aspect of the recommendations is also based on a comparative analysis of the kinetic characteristics (passports) of drill bits of different designs of identical and related types. The only difference is that the search for a more efficient drill bit for the given geological and technical conditions is carried out according to their catalog, i.e. among the already existing range of their designs, modifications, types.

\section{Analysis of the kinetic passport of the bit 215.9 SM}

The kinetic passport of the bit in tabular and graphical forms is presented below (Table 1 and Fig. 1).

The minimum values of the specific volumetric work are on the peripheral crown of the third cone, the second from the periphery of the crown of the second cone and the second from the periphery of the crown of the first cone.

$$
A^{\prime \prime}{ }_{\text {min I }}=17.371 \mathrm{~N} / \mathrm{mm}^{2}, A^{\prime \prime}{ }_{\text {min II }}=9.669 \mathrm{~N} / \mathrm{mm}^{2}, A^{\prime \prime}{ }_{\text {min III }}=8.194 \mathrm{~N} / \mathrm{mm}^{2} \text {. }
$$

The maximum load during the drilling process will be unevenly distributed, which will negatively affect the bit stability.

Table 1. Passport of the drill bit III 215.9 SM.

\begin{tabular}{|c|c|c|c|c|c|c|c|c|c|}
\hline \multirow{2}{*}{\multicolumn{3}{|c|}{$\begin{array}{l}\text { Ring sections at the } \\
\text { bottom from the } \\
\text { periphery to the center }\end{array}$}} & \multicolumn{6}{|c|}{ The wear rate of the crowns (in conv. units) $A^{\prime}$} & \multirow{3}{*}{$\begin{array}{l}\text { The intensity of } \\
\text { the face } \\
\text { destruction (in } \\
\text { conv. units) } A^{\prime \prime}\end{array}$} \\
\hline & & & \multicolumn{2}{|c|}{$\begin{array}{c}\text { Cone I } \\
i=1.400\end{array}$} & \multicolumn{2}{|c|}{$\begin{array}{c}\text { Cone II } \\
i=1.338\end{array}$} & \multicolumn{2}{|c|}{$\begin{array}{c}\text { Cone III } \\
i=1.378\end{array}$} & \\
\hline$j$ & $R$ & $D$ & $Z$ & $A^{\prime}$ & $Z$ & $A^{\prime}$ & $Z$ & $A^{\prime}$ & \\
\hline 1 & 107.95 & 5.740 & 15.0 & 41.521 & 14.0 & 42.452 & 13.0 & 41.677 & 46.411 \\
\hline 2 & 101.97 & 0.484 & 15.0 & 3.955 & 14.0 & 5.104 & 13.0 & 4.224 & 30.036 \\
\hline 3 & 101.00 & 1,449 & 30.0 & 3.862 & 28.0 & 4.943 & 26.0 & 4.106 & 58.952 \\
\hline 4 & 99.25 & 2.045 & 15.0 & 3.720 & 14.0 & 4.662 & 13.0 & 3.911 & 28.591 \\
\hline 5 & 97.21 & 2.045 & 15.0 & 3.607 & 14.0 & 4.354 & 13.0 & 3.726 & 27.764 \\
\hline 6 & 94.94 & 2.502 & 15.0 & 3.561 & & & 13.0 & 3.587 & 17.371 \\
\hline 7 & 92.47 & 2.436 & & & & & 13.0 & 3.532 & 8.194 \\
\hline 8 & 90.03 & 2.436 & & & & & 13.0 & 3.583 & 8.539 \\
\hline 9 & 87,59 & 2,436 & & & & & 13.0 & 3.736 & 9.151 \\
\hline 10 & 85.38 & 1.996 & & & & & 13.0 & 3.891 & 9.457 \\
\hline 11 & 81.77 & 2.971 & & & 14.0 & 3.537 & & & 9.669 \\
\hline 12 & 78.80 & 2.970 & & & 14.0 & 3.628 & & & 10.293 \\
\hline 13 & 75.83 & 2,970 & & & 14.0 & 3.751 & & & 11.062 \\
\hline 14 & 72.86 & 2,969 & & & 14.0 & 3.906 & & & 11.990 \\
\hline 15 & 61.74 & 2.866 & 12.0 & 5.969 & & & & & 19.321 \\
\hline
\end{tabular}


Continuation of the Table 1

\begin{tabular}{|c|c|c|c|c|c|c|c|c|c|}
\hline \multirow{2}{*}{\multicolumn{3}{|c|}{$\begin{array}{l}\text { Ring sections at the } \\
\text { bottom from the } \\
\text { periphery to the center }\end{array}$}} & \multicolumn{6}{|c|}{ The wear rate of the crowns (in conv. units) $A^{\prime}$} & \multirow{3}{*}{$\begin{array}{l}\text { The intensity of } \\
\text { the face } \\
\text { destruction (in } \\
\text { conv. units) } A^{\prime \prime}\end{array}$} \\
\hline & & & \multicolumn{2}{|c|}{$\begin{array}{c}\text { Cone I } \\
i=1.400\end{array}$} & \multicolumn{2}{|c|}{$\begin{array}{c}\text { Cone II } \\
i=1.338\end{array}$} & \multicolumn{2}{|c|}{$\begin{array}{c}\text { Cone III } \\
i=1.378\end{array}$} & \\
\hline$j$ & $R$ & $D$ & $Z$ & $A^{\prime}$ & $Z$ & $A^{\prime}$ & $Z$ & $A^{\prime}$ & \\
\hline 16 & 58.87 & 2.865 & 12.0 & 6.005 & & & & & 20.391 \\
\hline 17 & 56.00 & 2.864 & 12.0 & 6.045 & & & & & 21.586 \\
\hline 18 & 53.14 & 2.863 & 12.0 & 6.090 & & & & & 22.928 \\
\hline 19 & 47.75 & 2.295 & & & & & 10.0 & 5.810 & 20.292 \\
\hline 20 & 45.46 & 2.294 & & & & & 10.0 & 5.869 & 21.543 \\
\hline 21 & 43.17 & 2.292 & & & & & 10.0 & 5.932 & 22.948 \\
\hline 22 & 40.88 & 2.290 & & & & & 10.0 & 6.001 & 24.535 \\
\hline 23 & 38.59 & 2.288 & & & & & 10.0 & 6.077 & 26.343 \\
\hline 24 & 33.51 & 2.282 & & & 7.0 & 5.524 & & & 19.360 \\
\hline 25 & 31.23 & 2.278 & & & 7.0 & 5.645 & & & 21.264 \\
\hline 26 & 28.95 & 2.273 & & & 7.0 & 5.779 & & & 23.528 \\
\hline 27 & 26.68 & 2.267 & & & 7.0 & 5.957 & & & 26.255 \\
\hline 28 & 24.42 & 2.259 & & & 7.0 & 6.092 & & & 29.595 \\
\hline 29 & 18.32 & 2.566 & 2.0 & 7.465 & & & & & 14.065 \\
\hline 30 & 15.77 & 2.530 & 2.0 & 7.739 & & & & & 17.187 \\
\hline 31 & 13.26 & 2.470 & 2.0 & 8.079 & & & & & 21.845 \\
\hline 32 & 10.84 & 2.363 & 2.0 & 8.510 & & & & & 29.424 \\
\hline 33 & 8.56 & 2.157 & 2.0 & 9.078 & & & & & 43.554 \\
\hline 34 & 6.58 & 1.714 & 2.0 & 9.863 & & & & & 31.579 \\
\hline
\end{tabular}
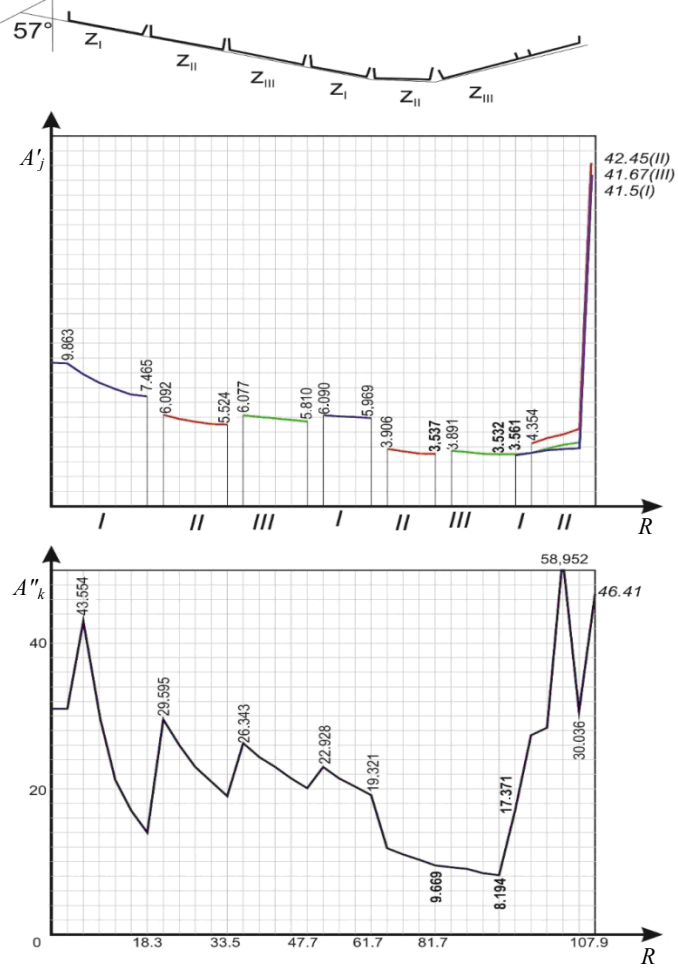

Fig. 1. Kinetic passport of the drill bit III 215.9 SM. 
Studies revealed that specific contact work of the destruction of the crowns' button depends on the geometric shape of the face. With roller cone bits forming a face shape with sharp angular sections, the maximum stress concentrations, as well as deformations in the rock and tooth, occur precisely in those sections of the face where the corresponding cone crown operates. Specific volumetric work depends on the path, speed, and duration and contact area of the buttons of the cones.

\section{Conclusions}

Recommended:

\section{I cone}

On the peripheral rim, increase the number of teeth from 15 to 16 , on the second rim from the periphery, increase the number of teeth from 12 to 13, the rest is unchanged.

II cone

On the peripheral crown, increase the number of teeth from 14 to 15.

III cone.

On the peripheral crown, increase the number of teeth from 13 to 16 , on the peripheral elongated crown, make a gap $2.5 \mathrm{~mm}$ wide at a distance from the center.

The kinetic passport of the recommended bit design is presented in tabular and graphical forms (Table 1, Fig. 1).

The advantages of the recommended placement of armament are as follows:

The potential of mechanical speed will increase due to increase

$$
A^{\prime \prime}{ }_{\text {min }} \text { from } 8.194 \text { to } 9.892 \mathrm{~N} / \mathrm{mm}^{2} \text {. }
$$

The bit stability will increase due to a more even load distribution between the supports of adjacent cones

$$
A^{\prime \prime}{ }_{\text {min I }}=9.892 \mathrm{~N} / \mathrm{mm}^{2}, A^{\prime \prime}{ }_{\text {min II }}=9.995 \mathrm{~N} / \mathrm{mm}^{2}, A^{\prime \prime}{ }_{\text {min III }}=10.085 \mathrm{~N} / \mathrm{mm}^{2} \text {. }
$$

This research work was conducted in the framework of the research plan of fundamental project of Tashkent State Technical University and Navoi State Mining Institute on the topic of "Development of the scientific basis for the construction of roller cone and combined drill bits for drilling blast holes in open cast mining" (State registration No. F2-006).

\section{References}

1. Toshov, J.B. (2016). The Questions of the Dynamics of Drilling Bit on the Surface of Well Bottom. Archives of Mining Sciences, 61(2), 275-283. https://doi.org/10.1515/amsc-2016-0020

2. Dong, G., \& Chen, P. (2017). A comparative experimental study of shale indentation fragmentation mechanism at the macroscale and mesoscale. Advances in Mechanical Engineering, 9(8), 168781401772624. https://doi.org/10.1177/1687814017726244

3. Cai, C., Wu, K. S., Lian, D., \& Yuan, X. H. (2015). Study of rock-breaking mechanism under single-tooth impact. Rock and Soil Mechanics, 36(6), 1659-1666.

4. Toshniyozov, L.G., \& Toshov, J.B. (2019). Analiz teoreticheskikh i eksperimental'nykh issledovaniy $\mathrm{v}$ oblasti protsessa sal'nikoobrazovaniya pri burenii skvazhin. Gornyy Informatsionno-Analiticheskiy Byulleten', (11), 139-151. http://doi.org/10.25018/0236-14932019-11-0-139-151

5. Tian, J., Zhang, T., Dai, L., Cheng, W., Yang, L., \& Yuan, C. (2018). Dynamic characteristics and test analysis of a new drilling downhole tool with anti-stick-slip features. Journal of Mechanical Science and Technology, 32(10), 4941-4949. https://doi.org/10.1007/s12206-0180942-X 
6. Liu, XD., \& Jun-Li, QU (2010). Optimization Research on the Main Geometrical Parameters of PDC Bit. Machinery Design \& Manufacture, (275), 803-807.

7. Chen, S., Arfele, R., Anderle, S., et al. (2013). A new theory on cutter layout for improving PDC bit performance in hard and transit formation drilling. SPE Drill Complete, (284), 338-349.

8. Mannanov, U., Toshov, J., \& Toshniyozov, L. (2019). Perspective Solutions for the Design of $\begin{array}{lllll}\text { Drilling Tools. E3S Web of Conferences, (105), } 03027 . & \end{array}$ https://doi.org/10.1051/e3sconf/201910503027

9. Toshov, Z.B. (2016). Ways towards optimization of washout components of rock cutting tools. Gornyi Zhurnal, 21-24. https://doi.org/10.17580/gzh.2016.02.04

10. Tian, J., Fu, C., Yang, L., Yang, Z., Pang, X., Li, Y., \& Liu, G. (2014). The Wear Analysis Model of Drill Bit Cutting Element with Torsion Vibration. Advances in Mechanical Engineering, 7(1), 254026. https://doi.org/10.1155/2014/254026

11. Baszynski, M., \& Rydygier, P., \& Wójcik, M. (2018). Experimental studies of: Laminate composition, drill bit wear out, and chloride ion concentration as factors affecting CAF formation rate. Microelectronics Reliability, (88-90), 31-37. 